\title{
Hot Rolled Ti6321 Alloy Sheets With Different Initial Microstructures: Microstructure, Mechanical Properties, and Anisotropy Characteristics
}

\author{
Jiangkun Fan ${ }^{1,2 * \dagger}$, Hao Huang ${ }^{1+}$, Xiangyi Xue ${ }^{1,2}$, Wenyuan Zhang ${ }^{1}$, Yang Wang ${ }^{3}$, \\ Binbin Zhang ${ }^{3}$, Bin Tang ${ }^{1,2}$, Ruifeng Zhao ${ }^{1,2,4}$, Hongchao Kou ${ }^{1,2}$ and Jinshan $\mathrm{Li}^{1,2}$ \\ ${ }^{1}$ State Key Laboratory of Solidification Processing, Northwestern Polytechnical University, Xi'an, China, ${ }^{2}$ National \& Local \\ Joint Engineering Research Center for Precision Thermoforming Technology of Advanced Metal Materials, Xi'an, China, ${ }^{3}$ The \\ 725 Research Institute of China Shipbuilding Industry Corporation, Luoyang, China, ${ }^{4}$ Chongqing Science and Technology \\ Innovation Center, Northwestern Polytechnical University, Chongqing, China
}

OPEN ACCESS

Edited by:

Linjiang Chai,

Chongqing University of

Technology, China

Reviewed by:

Ruifeng Dong,

North University of China, China

Ke Wang,

Chongqing University, China

*Correspondence:

Jiangkun Fan

jkfan@nwpu.edu.cn

tThese authors have contributed equally to this work

Specialty section: This article was submitted to

Structural Materials,

a section of the journal

Frontiers in Materials

Received: 14 March 2020

Accepted: 09 April 2020

Published: 27 May 2020

Citation:

Fan J, Huang $H$, Xue $X$, Zhang $W$, Wang $Y$, Zhang $B$, Tang $B$, Zhao $R$,

Kou H and Li J (2020) Hot Rolled

Ti6321 Alloy Sheets With Different Initial Microstructures: Microstructure,

Mechanical Properties, and Anisotropy Characteristics.

Front. Mater. 7:110

doi: 10.3389/fmats.2020.00110
The microstructure, mechanical properties, and texture characteristics of marine titanium alloy Ti6321 sheets with four different initial microstructures were investigated contrastively in this paper. The results indicate that the strength of hot-rolled, equiaxed, and bimodal microstructure sheets exhibits significant anisotropy in the RD and TD directions. The hot rolled sheet shows the strongest anisotropy of tensile properties, that is, the transverse yield strength is $91 \mathrm{MPa}$ higher than that of the rolling direction. The morphology characteristics of the macroscopic tensile fracture are also significantly different in RD and TD. The strength anisotropy of Ti6321 alloy sheet decreases with the increase of annealing temperature. The mechanical properties of the widmanstätten microstructure sheet are close to isotropic, and the plasticity is the worst among the four initial microstructures. The root cause for the properties anisotropy was analyzed by $X R D$ and EBSD. There is a strong $(\overline{1} 2 \overline{1} 0)[10 \overline{1} 0]$ prismatic texture and a relatively weak (1210)[0001] basal texture in the anisotropic sheet. The anisotropic characteristics of the tensile deformation of Ti6321 alloy sheet at room temperature are mainly attributed to the difference in the Schmid factor of the basal $<$ a $>$ slip system and prismatic $<$ a $>$ slip system in TD and RD specimens.

Keywords: near $\alpha$ titanium alloy, microstructure, mechanical property, texture, anisotropy

\section{INTRODUCTION}

Due to the high strength-weight ratio, good weldability, and excellent corrosion resistance, near $\alpha$ titanium alloys [such as Ti-6Al-2Zr-1Nb-1Mo (Wang et al., 2018) and Timetal 834 (Chandra Rao et al., 2009)] can effectively reduce the weight of ships and the cost of corrosion resistance, which has a huge potential application in marine engineering (Gurrappa, 2003; Banerjee and Williams, 2013; Yan et al., 2018). Generally, the mechanical properties of titanium alloys depend on the characteristics of the microstructure, and the microstructure of the alloy is decisively affected by the processing technology (Lutjering, 1998; Zhang and Chen, 2019; Dong et al., 2020; Zhang et al., 2020). The equiaxed microstructure has a high fatigue strength when compared 
to other microstructures (Tan et al., 2015), while other studies have shown that the bimodal or widmanstätten (lamellar) microstructure have better fatigue properties (Wu et al., 2013). The bimodal microstructure is usually selected as the final microstructure in the engineering application because of its good balance of strength and ductility (Yan et al., 2018). The widmanstätten structure usually has high resistance to fatigue crack propagation and impact toughness, and its properties are sensitive to the thickness of lamellar $\alpha$ phase (Semiatin and Bieler, 2001; Nalla et al., 2002). Therefore, it is necessary to carry out related research on the different microstructures of each potential alloy in order to grasp its characteristics, and then achieve precise control and optimization of the microstructure and mechanical properties.

Near $\alpha$ titanium alloys are mainly composed of an $\alpha$ phase at room temperature. The intense texture often exists in titanium alloys due to the fact that the $\alpha$ phase has a Hexagonal Closepacked (HCP) structure, which results in drastic anisotropy of mechanical properties (Singh and Schwarzer, 2000). Won et al. $(2015,2016)$ studied the anisotropy of mechanical properties and deformation characteristics of the pure Ti. They found that, in rolled pure $\mathrm{Ti}$, when the load is along $\mathrm{RD}$ and $\mathrm{TD}$, the slip is mainly a prismatic $<$ a $>$ slip with lower critical shear stress, and, when the load is along ND, the slip is mainly a basal $<$ a $>$ slip with higher critical resolved shear stress (CRSS). Bache and Evans (2001) and Bache et al. (2001) concluded that the orientation of the principal stress axis with respect to the dominant basal plane texture has a significant effect on the strength and fatigue properties under the tensile condition. (I). Bantounas and Trevor Lindley (2007) studied the effects of microtexture on fatigue cracking in Ti-6Al-4V and found that cracks usually arrest when confronted by grains unfavorably oriented for prismatic $<a>$ slip and favorably oriented for an $<\mathrm{c}+\mathrm{a}>$ slip in specimens with specific microtexture. Some studies have pointed out that there is obvious texture in the hot rolled near- $\alpha$ titanium alloy (Li et al., 2017, 2019). However, relatively little research has been done on the texture characteristics of different microstructures of near $\alpha$ titanium alloy. For the Ti-6Al-3Nb-2Zr-1Mo (Ti6321) alloy studied in the present work, the texture characteristics and anisotropy of different initial microstructure characteristics are not systematically investigated, and the essential mechanism analysis is also insufficient.

In this paper, Ti6321 alloy sheets with different microstructure characteristics were obtained by different heat treatment processes. The microstructure/texture evolution, mechanical properties, and anisotropy characteristics of the rolled Ti6321 alloy sheets with four different initial microstructures were systematically analyzed. The results are expected to provide useful information for the microstructure control and anisotropy research of near $\alpha$ titanium alloy.

\section{EXPERIMENTAL PROCEDURE}

\section{Materials}

The material used in the experiment was hot rolled Ti6321 alloy, and the $\beta$ transition temperature was approximately $985^{\circ} \mathrm{C}$. The alloy composition test results are shown in Table 1. The
TABLE 1 | Chemical composition of hot rolled Ti6321 alloy (wt\%).

\begin{tabular}{cccccccccc}
\hline $\mathbf{T i}$ & $\mathbf{A l}$ & $\mathbf{N b}$ & $\mathbf{Z r}$ & $\mathbf{M o}$ & $\mathbf{F e}$ & $\mathbf{O}$ & $\mathbf{N}$ & $\mathbf{C}$ & $\mathbf{H}$ \\
\hline Bal. & 6.08 & 2.94 & 2.02 & 1.02 & 0.038 & 0.071 & 0.003 & 0.005 & 0.001
\end{tabular}

TABLE 2 | Three different annealing treatments and corresponding microstructure of Ti6321 alloy.

\begin{tabular}{lcll}
\hline Temperature & Time & Cooling mode & Microstructure \\
\hline $900^{\circ} \mathrm{C}$ & $1 \mathrm{~h}$ & $\mathrm{AC}$ & Equiaxed \\
$970^{\circ} \mathrm{C}$ & $1 \mathrm{~h}$ & $\mathrm{AC}$ & Bimodal \\
$1,020^{\circ} \mathrm{C}$ & $45 \mathrm{~min}$ & $\mathrm{AC}$ & Widmanstätten \\
\hline
\end{tabular}

Ti6321 alloy sheet was obtained through two passes rolling in the $\alpha+\beta$ phase field and one pass of reverse rolling. Then, the hot rolled alloy was annealed at three different temperatures to obtain the equiaxed microstructure, bimodal microstructure, and widmanstätten microstructure. The detailed annealing heat treatment processes are shown in Table 2.

\section{Property Testing at Room Temperature}

Tensile tests were carried out according to GB/T 228.1-2010 at room temperature. The tensile standard specimens were cut along the rolling direction (RD) and transverse direction (TD) of the alloy sheet to study the anisotropic characteristics of the properties of the alloy sheet. Three groups of parallel experiments were set up for each condition to eliminate accidental errors. The bar specimens with a gauge length of $25 \mathrm{~mm}$ and gauge diameter of $5 \mathrm{~mm}$ were machined for tensile test, as shown in Figure 1A.

\section{Microstructure Characterization and Texture Detection}

The microstructure of the alloy was observed by optical microscope (OM, OLYMPUS GX71), scanning electron microscope (SEM, FEI Helios Nano Lab G3 UC) equipped with an EBSD acquisition camera, and the Aztec online acquisition software package. All the samples for OM, SEM, and EBSD examinations were mechanically using grit papers with different particle sizes from $80 \#$ to $2,000 \#$ and then were electro-polished with a solution of $60 \%$ methanol, $35 \%$ butyl alcohol, and 5\% perchloric acid. The samples used for the morphology observation were subjected to metallographic corrosion after polishing. Nano-scale microstructures were analyzed by transmission electron microscopy (TEM, FEI Talos F200X TEM) operated at $200 \mathrm{kV}$. The TEM foil specimens were prepared firstly by mechanical thinning to about $50 \mu \mathrm{m}$ in thickness, punched into disk of $3 \mathrm{~mm}$, and thinned by twin-jet electro polishing with a solution of $20 \%$ perchloric acid in methanol at a voltage of $40 \mathrm{~V}$. The fracture morphology of the tensile specimen was observed by SEM. Before the observation, the fracture specimen was cleaned ultrasonically.

The texture was tested by XRD on Bruker D8 advance. Five incomplete pole figures were measured to calculate the orientation distribution function (ODF). Only $\alpha$ phase was 

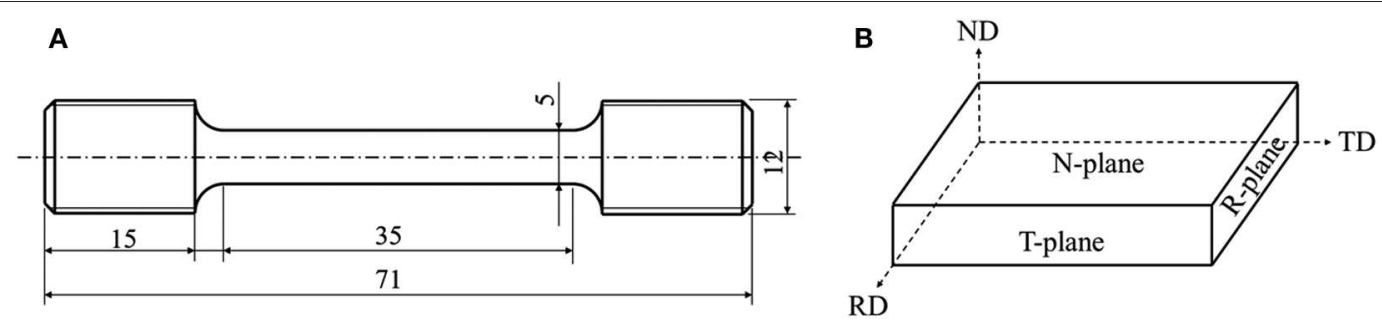

FIGURE 1 | (A) Geometries of the tensile specimen of Ti6321 alloy sheet; (B) Schematic diagram of rolling deformation coordinates of the Ti6321 alloy sheet.
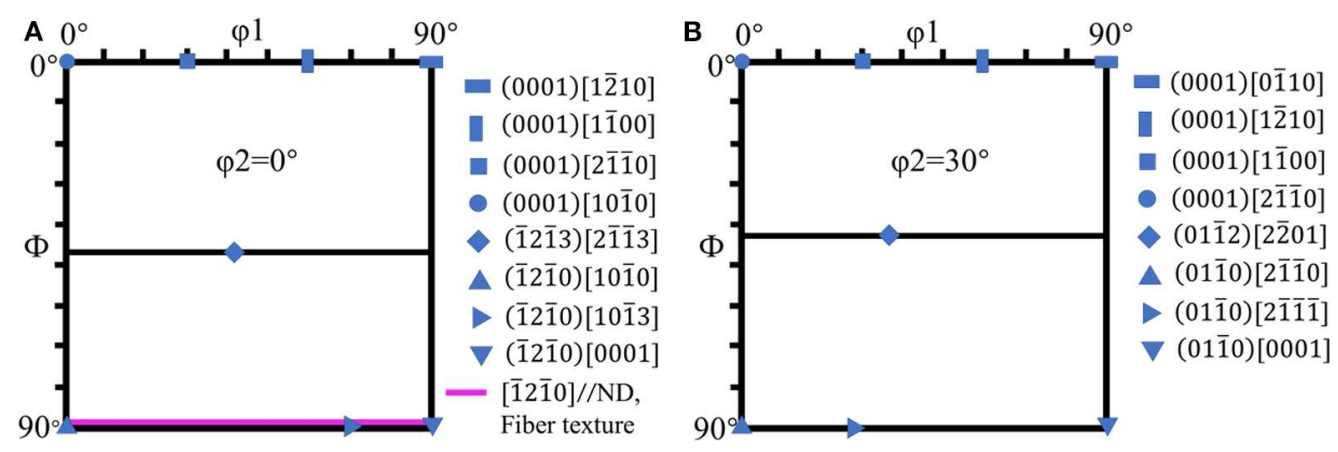

FIGURE 2 | The standard ODF maps of HCP: (A) $\phi 2=0^{\circ}$ (B) $\phi 2=30^{\circ}$.

measured because near- $\alpha$ titanium alloy is mainly composed of $\alpha$ phase at room temperature. In order to make accurate analysis on typical texture, constant $\phi 2=0^{\circ} \& 30^{\circ}$ ODF map were used. The standard ODF map and miller indices of texture orientation were calculated by Equation. (1) and Equation. (2) (Taylor Francis Group, 2010) shown in Figures 2A,B. $\{\phi 1 \varphi \phi 2\}$ is Euler angle.

$$
\begin{aligned}
& {\left[\begin{array}{l}
H \\
K \\
I \\
L
\end{array}\right]=\left[\begin{array}{ccc}
\frac{\sqrt{3}}{2} & \frac{-1}{2} & 0 \\
0 & 1 & 0 \\
\frac{-\sqrt{3}}{2} & \frac{-1}{2} & 0 \\
0 & 0 & \frac{c}{a}
\end{array}\right] \cdot\left[\begin{array}{c}
\sin \varnothing \sin \varphi 2 \\
\sin \varnothing \cos \varphi 2 \\
\cos \varnothing
\end{array}\right]} \\
& {\left[\begin{array}{c}
U \\
V \\
T \\
W
\end{array}\right]=\left[\begin{array}{ccc}
\frac{1}{\sqrt{3}} & \frac{-1}{3} & 0 \\
0 & \frac{2}{3} & 0 \\
\frac{-1}{\sqrt{3}} & \frac{-1}{3} & 0 \\
0 & 0 & \frac{c}{a}
\end{array}\right] \cdot\left[\begin{array}{c}
-\cos \varnothing \sin \varphi 1 \sin \varphi 2+\cos \varphi 1 \cos \varphi 2 \\
-\cos \varnothing \cos \varphi 2 \sin \varphi 1-\cos \varphi 1 \sin \varphi 2 \\
\sin \varnothing \sin \varphi 1
\end{array}\right]}
\end{aligned}
$$

\section{RESULTS AND DISCUSSION Characteristics of the Four Different Initial Microstructures}

In order to fully reveal the microstructure characteristics of Ti6321 alloy, the R-plane, T-plane, and N-plane of the alloy sheets were observed. Figure 3 shows the 3D metallography of four kinds of sheets. As shown in Figure 3A, the $\alpha$ phase on the T-plane and the R-plane are elongated toward TD and RD, respectively, in hot rolled sheets, and the size of $\alpha$ phase in $\mathrm{N}$ plane is larger. The microstructure of the sheet annealed at $900^{\circ} \mathrm{C}$ is similar to that of the hot rolled, but the equiaxed degree of $\alpha$ phase on three observation surfaces is increased (Figure 3B). With the increase in annealing temperature, more and more primary $\alpha$ phases dissolve into $\beta$ phase, and the $\alpha_{\mathrm{s}}$ (secondary $\alpha$ ) phase precipitates in $\beta$ phase during the subsequent air-cooling process. As a result, the microstructure gradually evolves into bimodal microstructure, which is composed of an $\alpha_{\mathrm{p}}$ (primary $\alpha$ ) phase and transformed $\beta$, as shown in Figure 3C. This indicates that the alloy undergoes a greater degree of $\alpha \rightarrow \beta$ transformation. When the annealing temperature rises above the $\beta$ transition point temperature, the grains of the alloy sheet become coarse and are filled with large number of lamellar $\alpha$ cluster structures (Figure 3D). Figure 4 shows the SEM images of N-plane of four different initial microstructures of Ti6321 alloy sheets. Both hot rolled and equiaxed microstructure sheets contain equiaxed and elongated $\alpha$ phases, but it is obvious that the proportion of elongated $\alpha$ phase is higher in hot rolled sheet. The bimodal microstructure sheet includes the equiaxed $\alpha_{p}$ phase and lamellar $\alpha_{s}$ phase, and there is almost no elongated $\alpha$ phase. The widmanstatten sheet includes the lamellar $\alpha_{\mathrm{s}}$ phase and a small amount of GB $\alpha$ (grain boundary $\alpha$ phase), as shown in the Figure 4d.

Figure 5 shows the TEM images of four different initial microstructures alloy sheets, and the microstructures are all composed of $\alpha$ and $\beta$ phases. Based on the quantitative statistics of a large number of OM, SEM, and TEM images, some characteristic parameters of the four different microstructures (N-plane) of the alloy sheets are shown in Table 3. Comparative statistics show that the volume fraction of primary $\alpha$ phase in the 

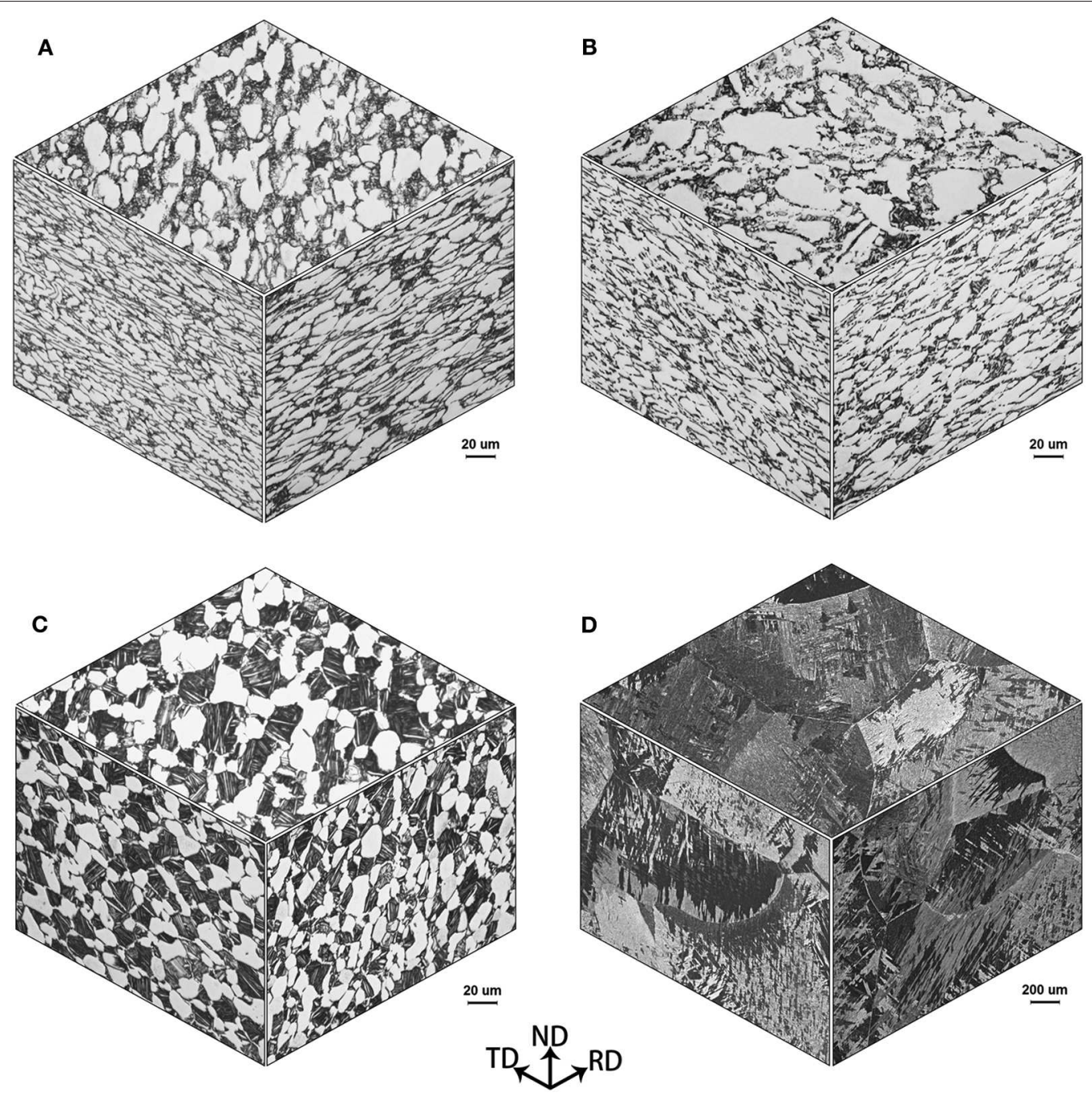

FIGURE 3 | 3D metallograph of four different initial microstructures of Ti6321 alloy sheets in RD-TD-ND directions: (A) Hot rolled sheet; (B) Equiaxed microstructure sheet; (C) Bimodal microstructure sheet; (D) Widmanstätten microstructure sheet.

equiaxed microstructure sheet is the highest, about $80.79 \%$. The size of the primary $\alpha$ phase in the bimodal microstructure sheet is the smallest $(10-20 \mu \mathrm{m})$. The length of the secondary $\alpha$ phase in widmanstätten microstructure sheet appears to range greatly $(20-160 \mu \mathrm{m})$. It should be noted that the original $\beta$ grains in the widmanstätten microstructure sheet become very coarse, and the size even reaches $2.3 \mathrm{~mm}$.

Figures 5A2, B2, C2, D2 shows that the content of Ti and Al in the $\alpha$ phase is significantly higher than that in the $\beta$ phase in these three kinds of microstructural sheets. However, the content of $\mathrm{Nb}$ and $\mathrm{Mo}$ in the $\beta$ phase is significantly higher. As a neutral element, $\mathrm{Zr}$ content in the two phases exhibits little difference. As shown in Figures $\mathbf{5 C 1}$, the bimodal microstructure sheet is composed of $\alpha_{p}$ and transformed $\beta$, and the width of the $\beta$ lamellae is about $100-400 \mathrm{~nm}$. The composition of two phases in the bimodal microstructure sheet is similar with that of the equiaxed sheet. For the widmanstätten microstructure sheet, the $\alpha$ lamellae grow in a certain direction in the $\beta$ grain, as shown in Figure 5D1. Obviously, when the heat treatment temperature is above the $\beta$ transition point, the difference of the content of alloying elements in the $\alpha_{\mathrm{s}}$ and $\beta$ phase decreases, indicating that the diffusion of elements is relatively uniform.

\section{Anisotropy of Mechanical Properties and Fracture Morphology}

The results of the tensile test are shown in the Table 4 and Figure 6. We can see that the hot rolled, equiaxed, and bimodal microstructure sheets show obvious anisotropy in mechanical properties. As shown in Figure 6C, the degree of anisotropy in the hot rolled sheet is the highest. The yield strength in TD of the hot rolled sheet is $91 \mathrm{MPa}$ higher than that of the RD. The anisotropy decreases with the increase of annealing temperature. In addition, the anisotropy of yield strength is higher than that of tensile strength. However, there was no obvious anisotropy in widmanstätten microstructure sheet. It is worth notice that the plasticity slightly increases with the increase of annealing 

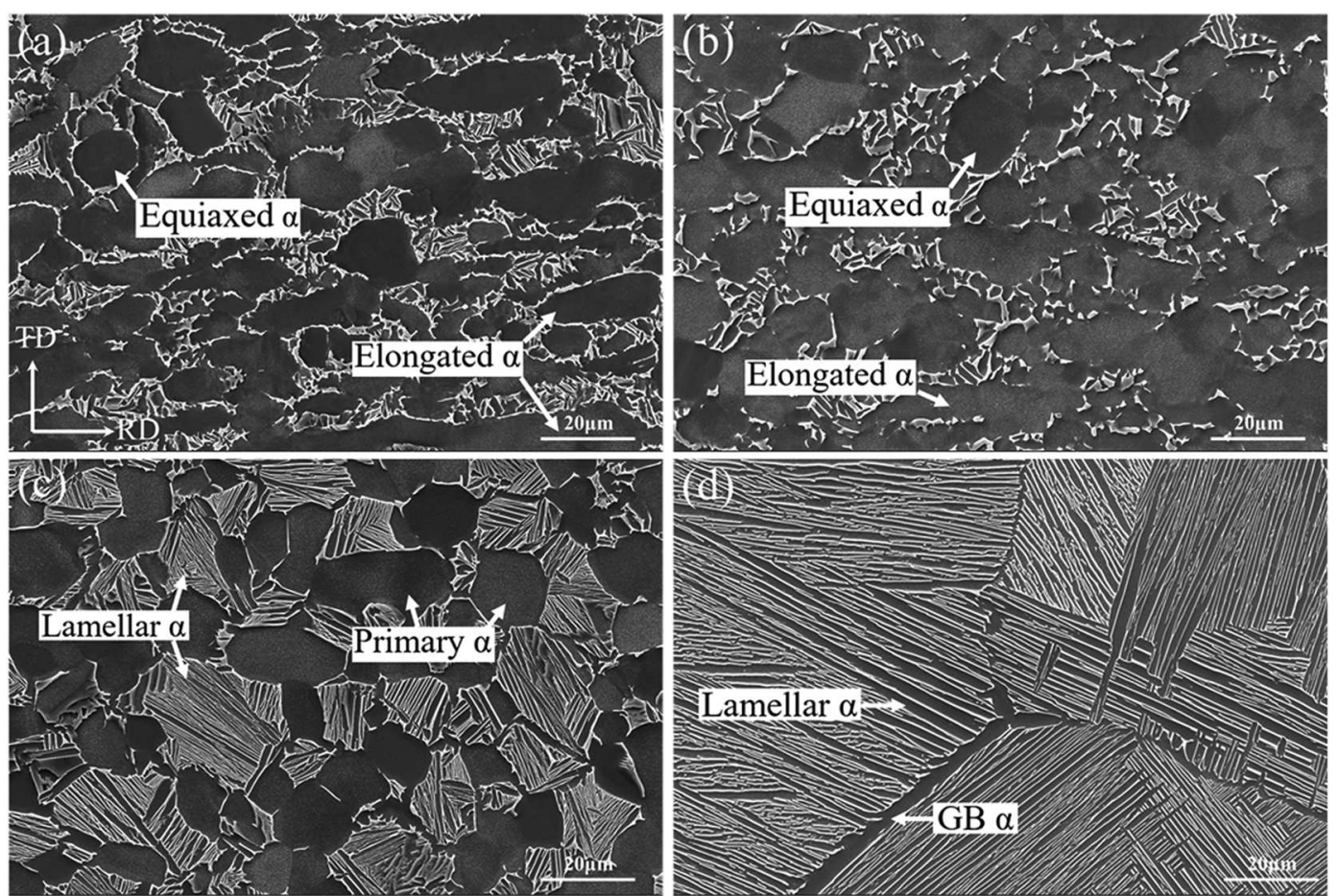

FIGURE 4 | SEM images of N-plane of four different initial microstructures of Ti6321 alloy sheets: (a) Hot rolled sheet; (b) Equiaxed microstructure sheet; (c) Bimodal microstructure sheet; (d) Widmanstätten microstructure sheet.
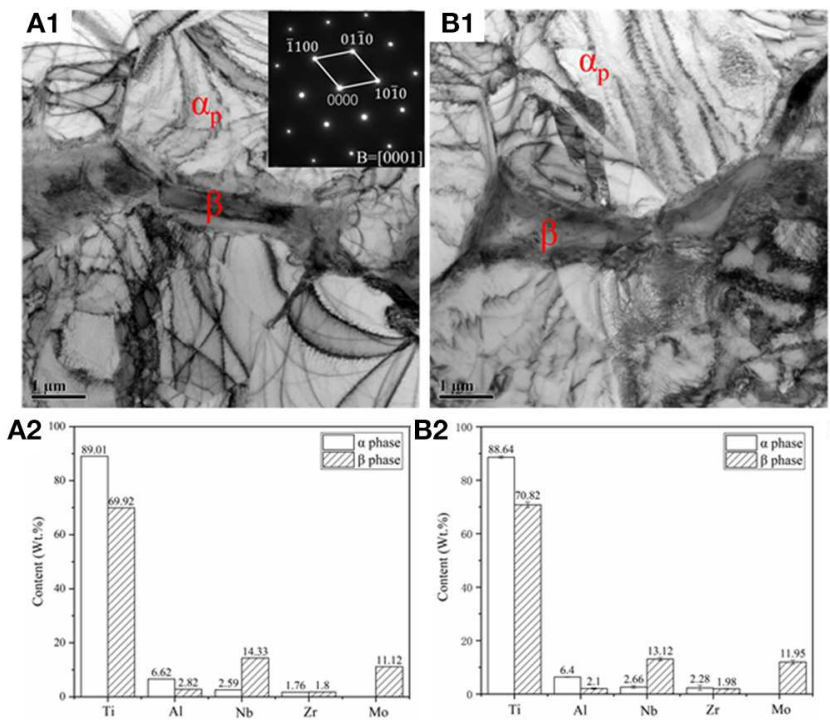
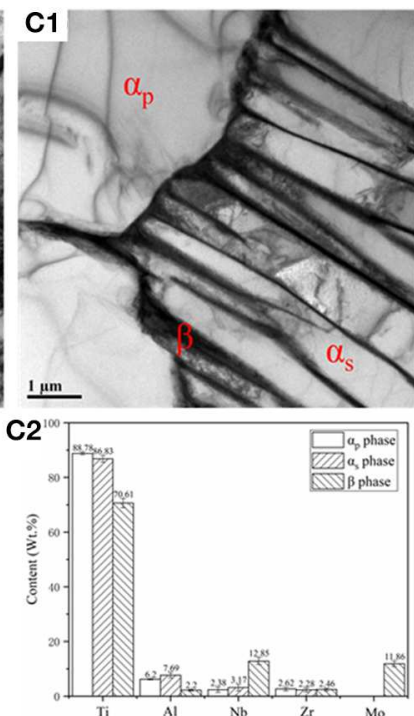

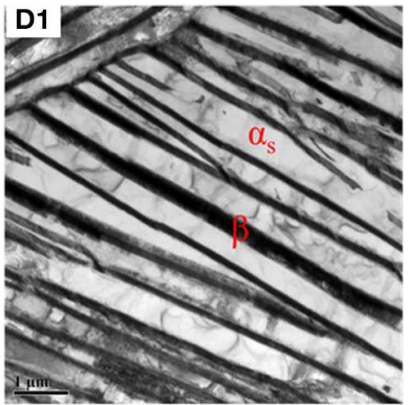

D2

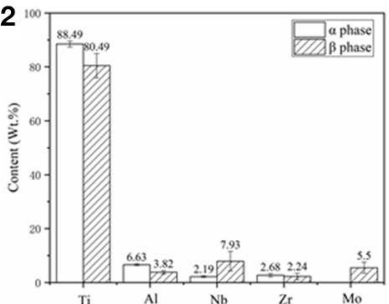

FIGURE 5 | TEM images of Ti6321 alloy and alloy element contents of $\alpha$ and $\beta$ phases: (A1, A2) Hot rolled microstructure; (B1, B2) Equiaxed microstructure; (C1, C2) Bimodal microstructure; (D1, D2) Widmanstätten microstructure.

temperature, but the plasticity of widmanstätten specimens are the worst.

The elongation of the three kinds of anisotropic sheets is similar, and there is no significant difference between RD and TD specimens. However, there is a significant difference between RD and TD specimens in the reduction of area, which is related to the morphology of the area. Among the three kinds of anisotropic sheets, the tensile fracture morphology of RD and TD is obviously different, as shown in Figure 8. The fracture surfaces in RD were pure shear fracture, which were about $45^{\circ}$ to the stress 
TABLE 3 | Quantitative statistics of different initial microstructures of Ti6321 alloy.

\begin{tabular}{|c|c|c|c|c|c|c|}
\hline Microstructure & Volume fraction of $\alpha_{p}(\%)$ & Size of $\alpha_{p}(\mu \mathrm{m})$ & Length of $\alpha_{s}(\mu \mathrm{m})$ & Width of $\alpha_{\mathrm{s}}(\mu \mathrm{m})$ & Width of $\mathrm{GB} \alpha(\mu \mathrm{m})$ & $\begin{array}{c}\text { Size of transformed } \beta \\
\text { grain }(\mu \mathrm{m})\end{array}$ \\
\hline Hot rolled & 70.66 & $15-30$ & $<10$ & $0.5-1.5$ & / & / \\
\hline Equiaxed & 80.79 & 20-35 & $<10$ & $0.5-1.5$ & / & / \\
\hline Bimodal & 40.60 & $10-20$ & 10-30 & $0.5-1.5$ & $1-1.5$ & $10-25$ \\
\hline Widmanstätten & / & / & $20-160$ & $0.5-1$ & $1-2$ & $1,200-2,300$ \\
\hline
\end{tabular}

TABLE 4 | Tensile properties of Ti6321 alloy sheets at room temperature.

\begin{tabular}{llllllll}
\hline Microstructure & Direction & $\begin{array}{c}\mathbf{R p 0 . 2} \\
\text { (MPa) }\end{array}$ & $\begin{array}{c}\mathbf{R m} \\
\mathbf{( M P a )}\end{array}$ & $\mathbf{A}(\%)$ & $\mathbf{Z}(\%)$ & $\mathbf{( M P a )}$ & $\mathbf{( M P a )}$ \\
\hline Hot rolled & RD & 800 & 887 & 15.0 & 38.4 & 91 & 77 \\
& TD & 891 & 964 & 15.8 & 51.4 & & \\
Equiaxed & RD & 794 & 872 & 15.5 & 38.6 & 86 & 74 \\
& TD & 880 & 946 & 15.8 & 50.2 & & \\
Bimodal & RD & 753 & 867 & 16.3 & 41 & 74 & 55 \\
& TD & 827 & 922 & 15.6 & 45.2 & & \\
Widmanstätten & RD & 764 & 873 & 8.6 & 14.1 & 6 & 8 \\
& TD & 758 & 865 & 7.1 & 15.8 & & \\
\hline
\end{tabular}

axis. Reversely, the fracture surfaces in TD were typical cup cone fracture. As shown in Figures 7a1, a2-c1, c2, the fracture of TD specimen is composed of the shear lip region and the fibrous region. The fracture surfaces of $\mathrm{RD}$ and $\mathrm{TD}$ specimens of these three kinds of sheets show obvious necking phenomenon, showing obvious plastic deformation characteristics. The fracture morphology of widmanstätten microstructure sheet is shown in Figures $7 \mathbf{d} \mathbf{1}, \mathbf{d} 2$. The fracture of RD and TD specimens are all irregular shear fracture. There is no obvious necking feature near the fracture, and the fracture is close to brittle fracture.

Figure 8 shows the microstructure on the longitudinal cross section of four kinds of sheets tensile specimens. The $\alpha$ phase in hot rolled, equiaxed, and bimodal sheets is obviously elongated along the tensile direction. However, no obvious elongated morphology was observed in widmanstätten specimens. This suggests that the plasticity of the first three kinds of microstructure sheets is better, and the obvious necking phenomenon occurs during the deformation, while the plasticity of the widmanstätten specimens is poor, and the necking is not obvious. In addition, as can be seen from Figure 8, there are lots of voids between 1 and $10 \mu \mathrm{m}$ at the boundary of $\alpha_{p}$ in hotrolled and equiaxed specimens, and the voids can grow through the $\alpha_{\mathrm{p}}$ phase. In the bimodal specimens, most of the voids are formed at the boundary of the globular primary $\alpha$ phase and transformed $\beta$, and they can also grow in the form of passing through the $\alpha_{\mathrm{p}}$ phase. However, for widmanstätten specimens, the voids can be generated at the boundary of lamellae colony or the boundary between grain boundary $\alpha$ phase and lamellae colony, and it can also be seen from the Figures 8d1, d2 that a large number of smaller voids are generated at the boundary of the secondary $\alpha$ phase.

\section{Preferred Crystallographic Orientation of the Alloy Sheet}

In order to reveal the essential cause of the anisotropy of the mechanical properties of the alloy sheet, the texture characteristics of the sheets with four different initial microstructures were systematically characterized and analyzed. It can be seen from Figure 9 that the texture characteristics of hot rolled, equiaxed, and bimodal specimens are similar. Their texture characteristics are mainly manifested in the ODF map of $\phi 2=0^{\circ}$. There are strong $(\overline{1} 2 \overline{1} 0)[10 \overline{1} 0]$ prismatic texture and relatively weaker $(\overline{1} 2 \overline{1} 0)[0001]$ basal texture in hot rolled, equiaxed microstructure and bimodal specimens, while their texture characteristics on the ODF map of $\phi 2=30^{\circ}$ are not obvious. This results show that the $(\overline{1} 2 \overline{1} 0)$ crystal plane of most grains in the sheets are approximately parallel to the N-plane, the

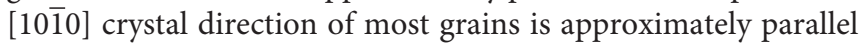
to the $\mathrm{RD}$, and the [0001] crystal direction of a small number of grains tends to be parallel to the RD. However, [ $\overline{1} 2 \overline{1} 0] / / \mathrm{ND}$ fiber texture was formed in the widmanstätten microstructure sheet. This means that most of the (12 $\overline{1} 0)$ crystal faces of the $\alpha$ phase in the sheet tend to be parallel to the N-plane, and their crystallographic $c$-axis directions are generally evenly distributed in all possible directions. In addition, it can be seen from Figure 9D2 that the characteristics of texture in the widmanstätten microstructure sheet are different from the other three sheets. The widmanstätten microstructure sheet exhibits a new weak texture in the ODF map of $\phi 2=$ $30^{\circ}$. Since the widmanstätten microstructure sheet is formed when the annealing temperature is higher than the $\beta$ phase transition point, the microstructure is a fully lamellar type, that is, the $\alpha$ phase inside the $\beta$ crystal grains is all the secondary $\alpha$ phase precipitated from the $\beta$ phase. The orientation of the $\alpha$ phase and the $\beta$ phase in the precipitation process is in accordance with the Burgers orientation relationship, and there are $12 \alpha$ variants for $\beta \rightarrow \alpha$ transition (Burgers, 1934; Cayron, 2008). Some previous studies have proposed that the variants selection might affect the texture characteristics (Li et al., 2019). Therefore, the texture characteristics of the widmanstätten microstructure sheet are different from the other three sheets.

Figures 10A,B shows the ( $\overline{1} 2 \overline{1} 0)[10 \overline{1} 0]$ and $(\overline{1} 2 \overline{1} 0)[0001]$ in the HCP structure. Combined with the analysis of ODF map, we could get the orientation of grain distribution in hot rolled, equiaxed, and bimodal microstructure sheets with anisotropy, and in widmanstätten microstructure sheet with [ $\overline{1} 2 \overline{1} 0] / / \mathrm{ND}$ fiber texture, as shown in Figures 10C,D. 

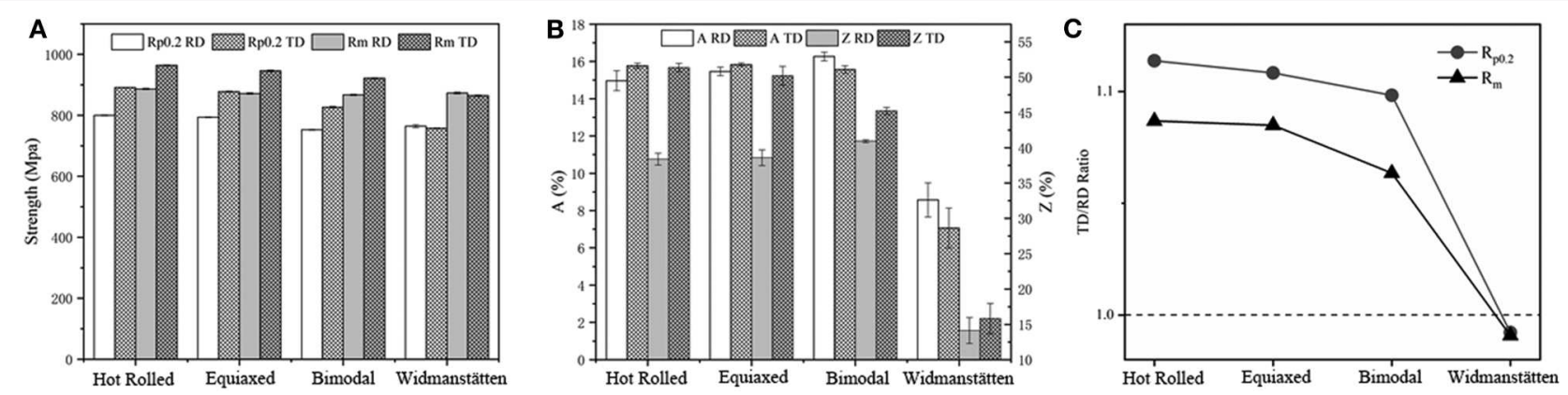

FIGURE 6 | Tensile test results of Ti6321 sheets: (A) Yield strength and tensile strength; (B) Elongation and reduction of area; (C) TD/RD ratio.
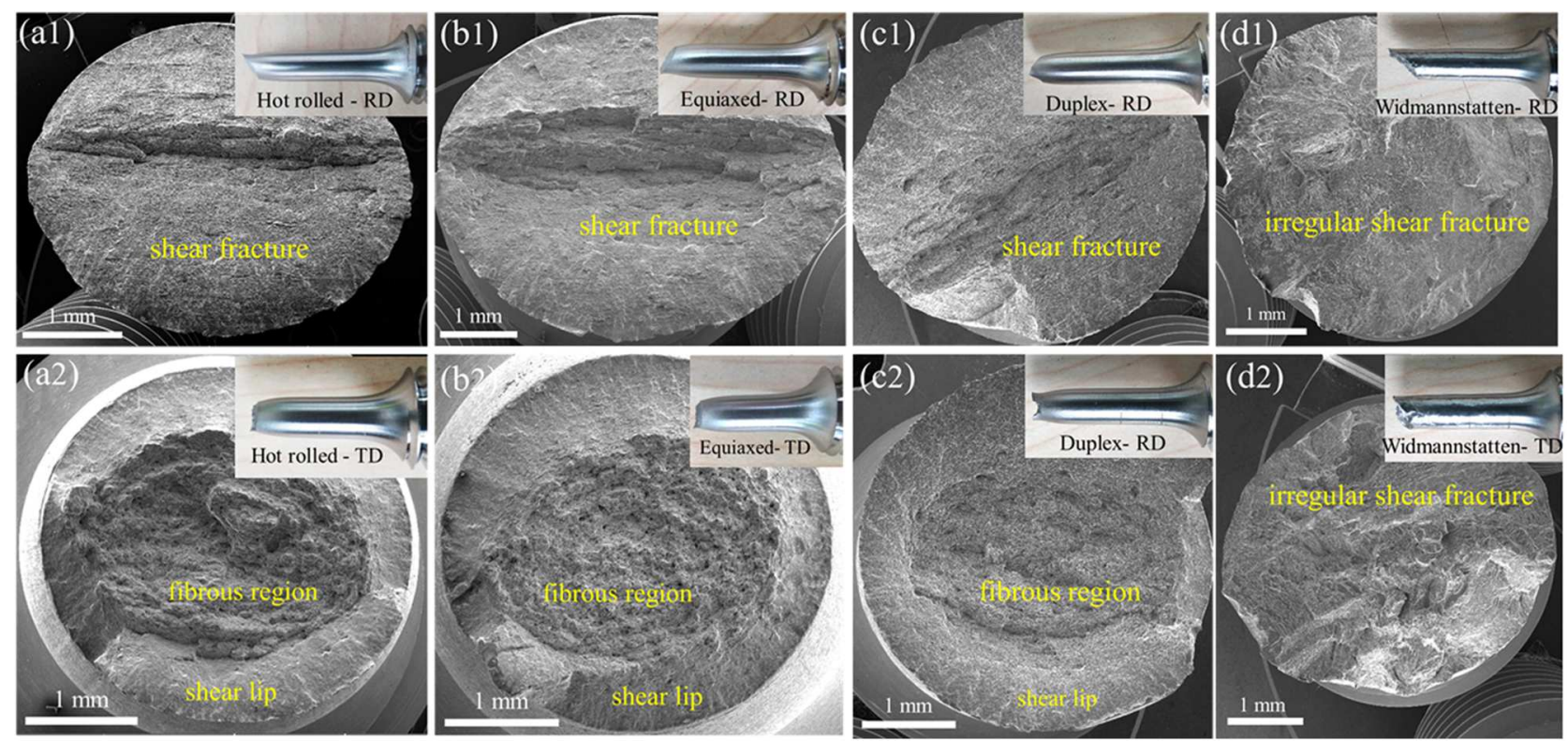

FIGURE 7 | Morphology of tensile fracture: (a1, a2) Hot rolled specimen; (b1, b2) Equiaxed specimen; (c1, c2) Bimodal specimen; (d1, d2) Widmanstätten specimen.

In this paper, EBSD analysis of bimodal sheet is carried out to explore the influence of texture on the deformation of samples in different directions. Textures in the bimodal microstructure sheets are shown in Figure 11, including (0002), (11 $\overline{2} 0)$, and (1010) pole figures. The (0002) poles have a peak close to TD with a high intensity, suggesting that $\mathrm{c}$ axis of $\alpha$ phase have a stronger tendency orientating toward $\mathrm{TD}$, which is consistent with the result of XRD texture test. This is a typical T-type texture usually found when titanium alloys were hot rolled at $\alpha+\beta$ field (Leyens and Peters, 2003). The intensity in (11 $\overline{2} 0)$ and $(10 \overline{1} 0)$ poles was relatively weak. Generally, the T-texture is formed because the slipping planes tends to rotate to a position parallel to the rolling plane during the rolling process (Dillamore and Roberts, 1965; Lee et al., 1988; Jean-Phillippe Thomas et al., 1997). Since the main deformation mechanism during plastic deformation is dislocation slip, it is important to analyze the influence of texture on slip. The most active slip systems in HCP metals are <a> type slips on the prismatic
$\{10 \overline{1} 0\}$ plane and on the basal (0001) plane (Chin and Mammel, 1970; Akhtar, 1975). However, $\alpha$-Ti has a smaller c/a value than other HCP structural materials, which is 1.587 . The prismatic $<$ a $>$ slips could be more active than the basal $<$ a $>$ slips due to the lower critical resolved shear stress (CRSS) (Yoo and Wei, 1967); this has been verified by the experimental results of single and poly crystal $\mathrm{Ti}$ and $\mathrm{Ti}$ alloys (Akhtar and Teghtsoonian, 1975; Jones and Hutchinson, 1981; Thomas Bieler and Semiatin, 2002; Kwai Chan, 2004; Gong and Angus Wilkinson, 2009; Li et al., 2013). Figures 11B,C shows the distribution of the Schmid factor when the RD and TD specimens are deformed under stress. When stress direction is parallel to $\mathrm{RD}$, Schmid factors of basal $<\mathrm{a}>$ slips and prismatic $<\mathrm{a}>$ slips in most of grains were in the range of 0.35-0.5, as shown in Figure 11B, meaning that both basal $<a>$ slips and prismatic $<a>$ slips were easily activated. In addition, we can see that the frequency of the high Schmid factor of the prismatic $<a>$ slips is higher than that of the basal $<a>$ slips, which indicates that the deformation 

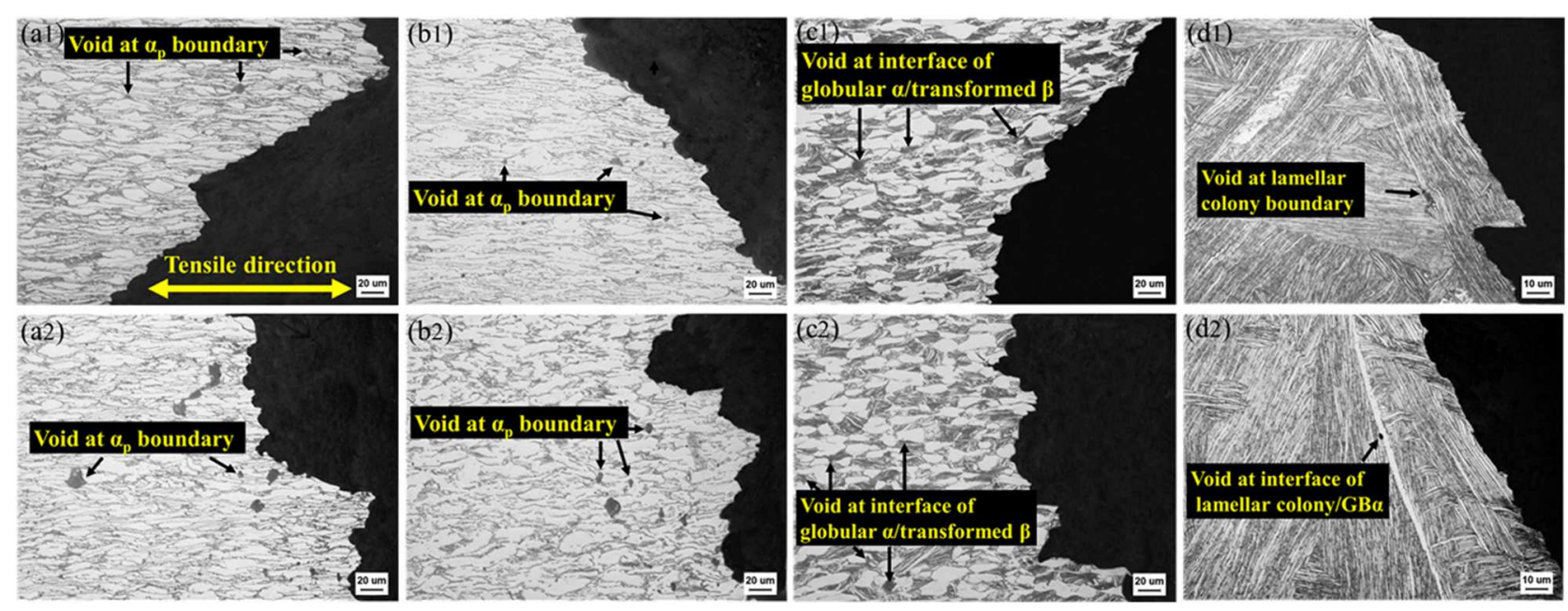

FIGURE 8 | Longitudinal cross-section of tensile specimens of four kinds of microstructure sheets: (a1, a2) Hot rolled specimen; (b1, b2) Equiaxed specimen; (c1, c2) Bimodal specimen; (d1, d2) Widmanstätten specimen; Corner markers 1 and 2 represent RD and TD, respectively.

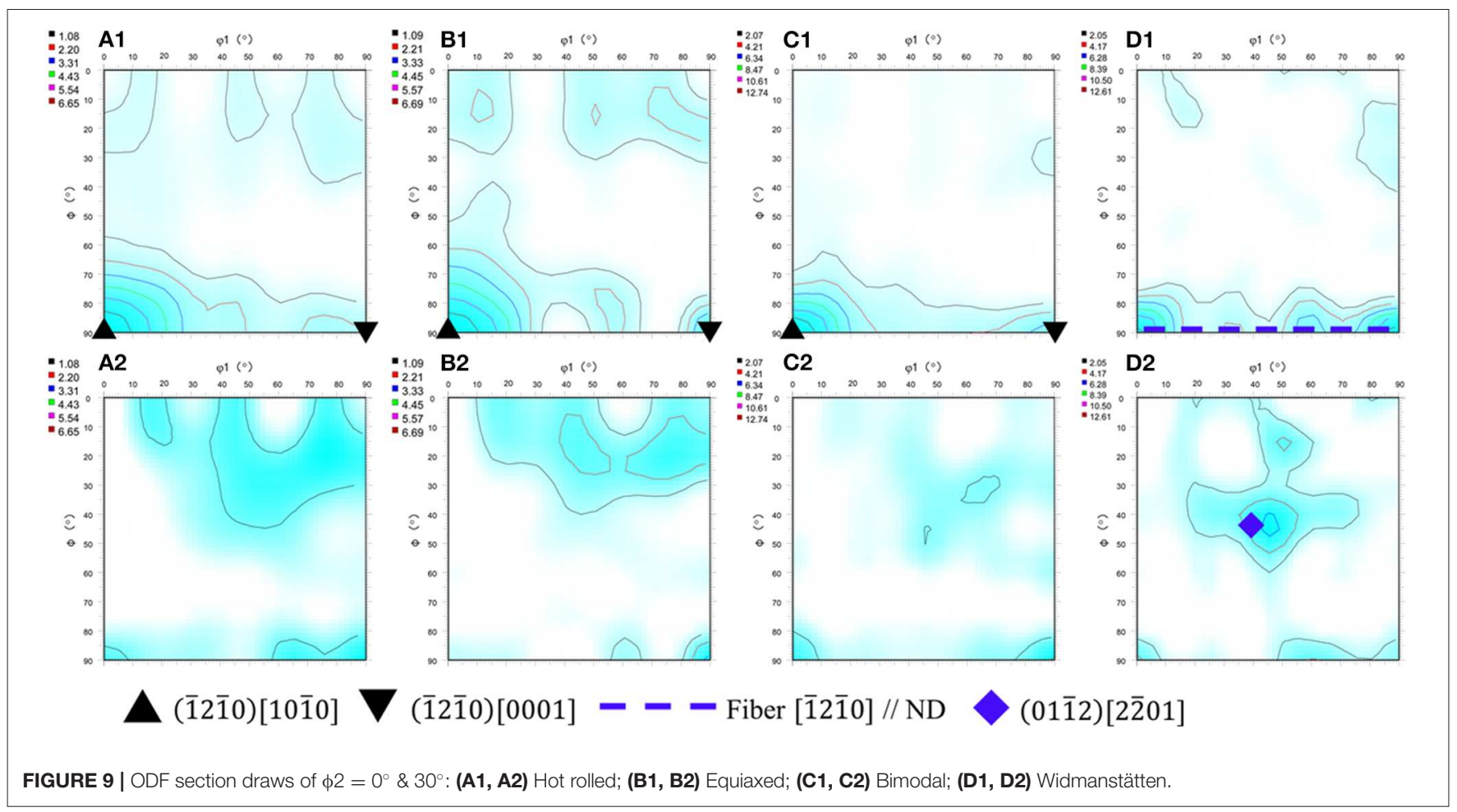

of the RD specimen is dominated by the prismatic $<\mathrm{a}>$ slips. However, when stress direction was parallel to TD, the Schmid factor distribution of most prismatic $<\mathrm{a}>$ slip is between 0 and 0.1 . The frequency of Schmid factor between 0.35 and 0.5 of basal $<\mathrm{a}>$ slips is slightly higher than that of prismatic $<\mathrm{a}>$ slips but lower than that of $\mathrm{RD}$ specimen. Considering that the CRSS of the prismatic <a $>$ type slip is lower than that of the basal $<a>$ slip, it is speculated that the deformation of the TD specimen may still be dominated by the prismatic $<$ a $>$ slip.

In summary, the presence of texture affects the distribution of the Schmid factor of the prismatic < a type slip and the basal $<$ a $>$ type slip in the different directions in the anisotropic sheets. This leads to the prismatic $<\mathrm{a}>$ type slip in TD specimens being more difficult to activate than in the RD specimens when the load is along $\mathrm{RD}$ and $\mathrm{TD}$, respectively, which leads to anisotropy. 

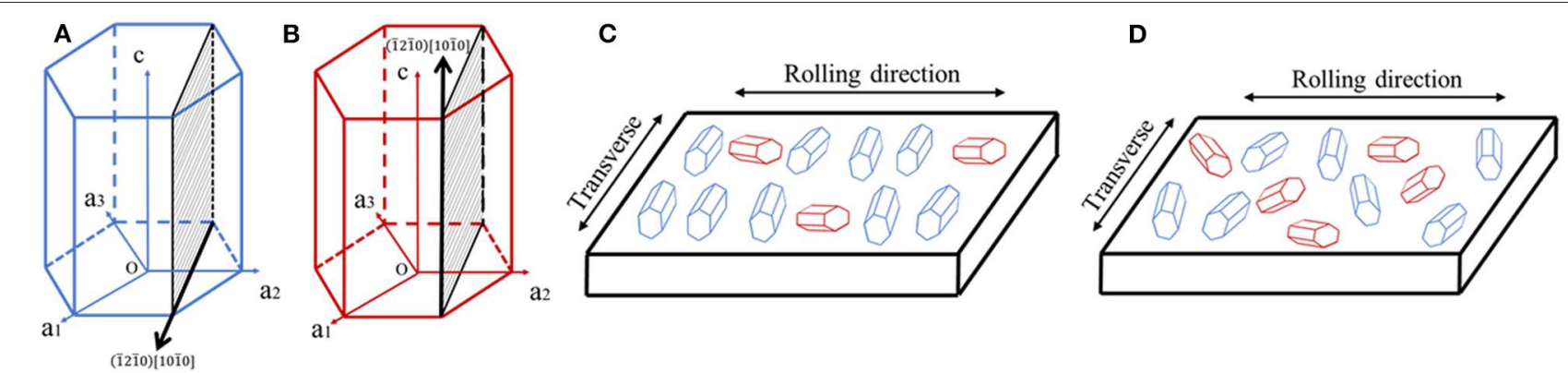

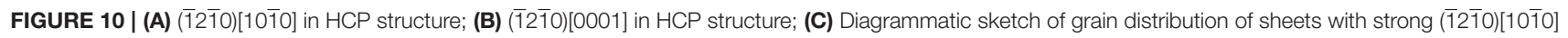

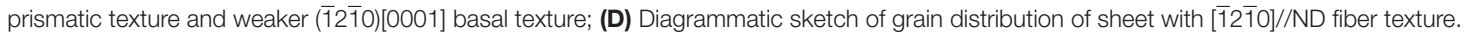
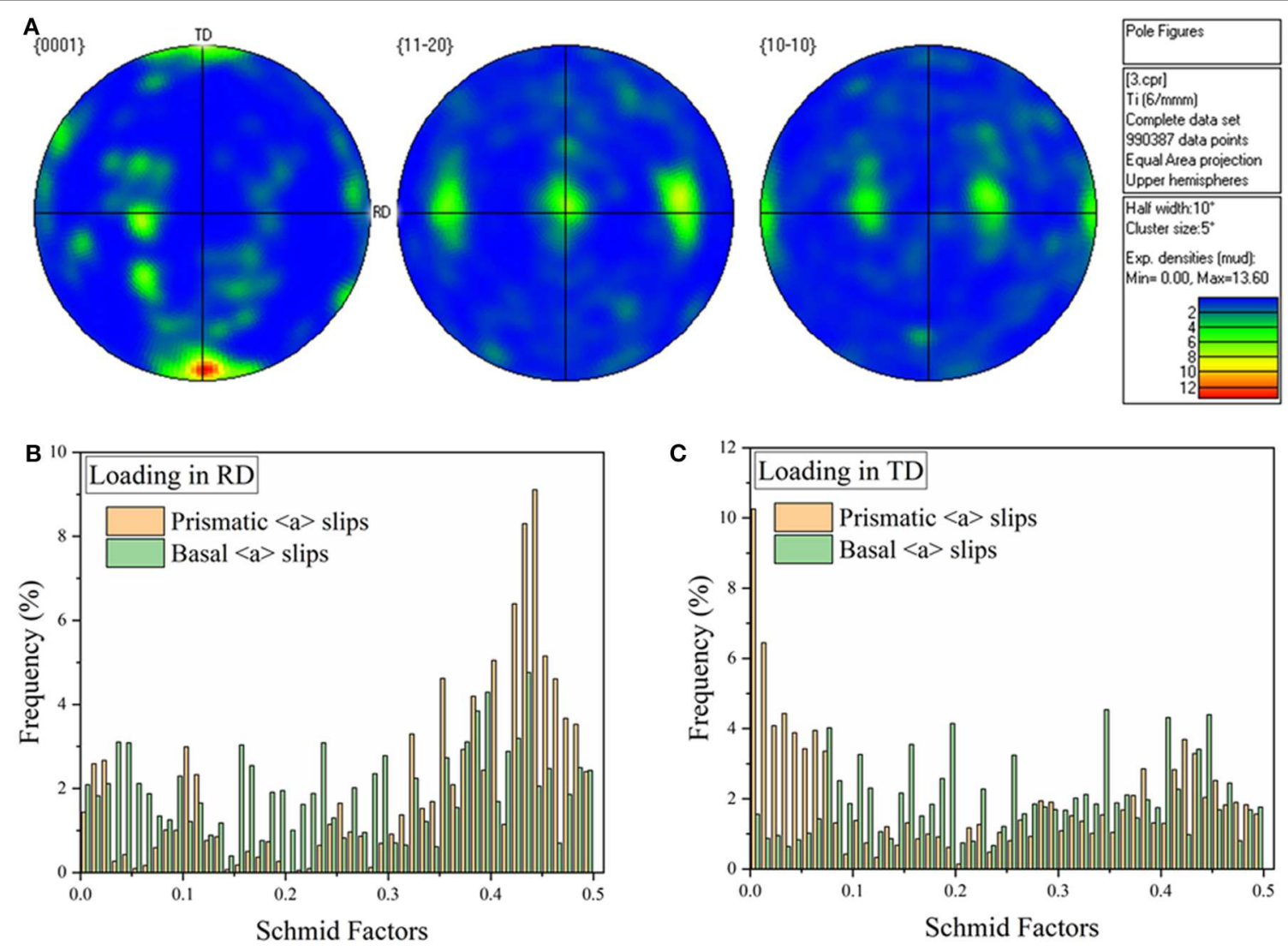

FIGURE 11 | Results of EBSD analysis. (A) Pole Figures and statistics of Schmid Factors of prismatic $<$ a $>$ slips and basal $<$ a $>$ slips when loading in (B) RD and (C) TD.

\section{CONCLUSIONS}

In the present work, the microstructure, mechanical properties, and texture analysis of four Ti6321 alloy sheets with different initial structures were carried out. Several conclusions can be drawn.

1) The hot rolled and equiaxed microstructure sheets have similar microstructural characteristics, and the $\mathrm{N}$-plane microstructure of these two sheets is quite different from that of R-plane and T-plane, which shows that the $\alpha$ phase of R-plane and T-plane has obvious deformation and elongation. There was no significant difference between the three observation surfaces of bimodal and widmanstätten microstructure sheets.

2) The hot rolled, equiaxed, and bimodal microstructure sheets exhibited significant anisotropy in the tensile test at room temperature, showing that the strength of TD is greater than $\mathrm{RD}$, and the $\mathrm{RD}$ and $\mathrm{TD}$ fracture morphology are quite 
different. The fracture of RD specimens is a shear fracture, while that of TD is a typical cup cone fracture. However, widmanstätten microstructure sheet has the worst plasticity and does not exhibit significant anisotropy. In the process of tensile deformation, microvoids are easy to form near the $\alpha_{\mathrm{p}}$ in hot rolled, equiaxed, and bimodal specimens, and the microvoids can expand in the form of passing through the $\alpha_{\mathrm{p}}$. In widmanstätten specimens, microvoids often generated at the boundary of $\alpha_{s}$ and $\mathrm{GB}_{\alpha}$ and can expand along $\alpha_{s}$ or through $\alpha_{s}$.

3) There is a strong $(\overline{1} 2 \overline{1} 0)[10 \overline{1} 0]$ prismatic texture and a weaker $(\overline{1} 2 \overline{1} 0)[0001]$ basal texture in the Ti6321 sheets with obvious anisotropic tensile behavior. However, the $[\overline{1} 2 \overline{1} 0] / / \mathrm{ND}$ fiber texture fiber texture was formed in the widmanstätten sheet. The formation of these textures results in significantly different distribution rules of the Schmid factor of the grains when the alloy is subjected to stress in different directions. The anisotropic characteristics of the tensile deformation of Ti6321 alloy sheet at room temperature are mainly attributed to the difference in the Schmid factor of basal $<$ a $>$ slip system and prismatic $<\mathrm{a}>$ slip system in TD and RD samples.

\section{REFERENCES}

Akhtar, A. (1975). Basal slip and twinning in $\alpha$-titanium single crystals. Metallurg. Mater. Trans. A. 6, 1105-1113. doi: 10.1007/BF02645537

Akhtar, A., and Teghtsoonian, E. (1975). Prismatic slip in $\alpha$-titanium single crystals. Metallurg. Mater. Trans. A. 6, 2201-2208. doi: 10.1007/BF02818644

Bache, M. R., and Evans, W. J. (2001). Impact of texture on mechanical properties in an advanced titanium alloy. Mater. Sci. Eng. A. 319, 409-414. doi: 10.1016/S0921-5093(00)02034-7

Bache, M. R., Evans, W. J., Suddell, B., and Herrouin, F. R. M. (2001). The effects of texture in titanium alloys for engineering components under fatigue. Int. J. Fatigue. 23, 153-159. doi: 10.1016/S0142-1123(01)00124-4

Banerjee, D., and Williams, J. C. (2013). Perspectives on titanium science and technology. Acta Mater. 61, 844-879. doi: 10.1016/j.actamat.2012.10.043

Bantounas, I., and Trevor Lindley, C. (2007). David Rugg, David Dye, effect of microtexture on fatigue cracking in Ti-6Al-4. Acta Mater. V 55, 5655-5665. doi: 10.1016/j.actamat.2007.06.034

Burgers, W. G. (1934). On the process of transition of the cubic-body-centered modification into the hexagonal-close-packed modification of zirconium. Physica 1, 561-586. doi: 10.1016/S0031-8914(34)80244-3

Cayron, C. (2008). Importance of the $\alpha \rightarrow \beta$ transformation in the variant selection mechanisms of thermomechanically processed titanium alloys. Scr. Mater. 59, 570-573. doi: 10.1016/j.scriptamat.2008.05.013

Chandra Rao, B. S. S., and Srinivas, M., Kamat, S. V. (2009). The effect of volume fraction of primary $\alpha$ phase on fracture toughness behavior of Timetal 834 titanium alloy under mode I and mixed mode I/III loading. Mater. Sci. Eng. A. 520, 29-35. doi: 10.1016/j.msea.2009.05.007

Chin, G., and Mammel, Y. W. L. (1970). Competition among basal, prism, and pyramidal slip modes in hcp metals. Metallurg. Mater. Trans. B. 1, 357-361. doi: $10.1007 / \mathrm{BF} 02811542$

Dillamore, I. L., and Roberts, W. T. (1965). Preferred orientation in wrought and annealed metals. Metallurg. Rev. 10, 271-380. doi: 10.1179/mtlr.1965.10.1.271

Dong, R., Li, J., Kou, H., Fan, J., Zhao, Y., Hou, H., et al. (2020). w-Assisted refinement of $\alpha$ phase and its effect on the tensile properties of a near $\beta$ titanium alloy. J. Mater. Sci. Technol. 44, 24-30 doi: 10.1016/j.jmst.2019. 10.031

Gong, J., and Angus Wilkinson, J. (2009). Anisotropy in the plastic flow properties of single-crystal $\alpha$ titanium determined from micro-cantilever beams. Acta Mater. 57, 5693-5705. doi: 10.1016/j.actamat.2009.07.064

\section{DATA AVAILABILITY STATEMENT}

The datasets generated for this study are available on request to the corresponding author.

\section{AUTHOR CONTRIBUTIONS}

$\mathrm{JF}$ and $\mathrm{HH}$ conceived experiments and wrote the paper. $\mathrm{HH}$, $\mathrm{WZ}, \mathrm{YW}$, and BZ performed experiments and data analysis. XX, $\mathrm{BT}$, and RZ assisted in standoff experimental set-up and analysis. $\mathrm{HK}$ and JL assisted in data analysis. All authors have given their approval to the final version of the manuscript.

\section{FUNDING}

The authors gratefully acknowledge the Major State Research Development Program of China (No. 2016YFB0701305), the National Natural Science Foundation of China (No. 51801156) and the Natural Science Basic Research Plan in Shaanxi Province of China (Nos. 2019JM-584 and 2018JQ5035) for the financial support to this work.

Gurrappa, I. (2003). Characterization of titanium alloy Ti-6Al-4V for chemical, marine and industrial applications. Mater. Character. 51, 131-139. doi: 10.1016/j.matchar.2003.10.006

Jean-Phillippe Thomas, A., Ramesh Minisandram, S., Robin Forbes Jones, M., and John Mantione, V. (1997). The thermomechanical processing of alpha/beta titanium alloys. JOM. 49, 33-39. doi: 10.1007/BF02914711

Jones, I. P., and Hutchinson, W. B. (1981). Stress-state dependence of slip in Titanium-6Al-4V and other H.C.P. metals. Acta Metallurgica. 29, 951-968. doi: 10.1016/0001-6160(81)90049-3

Kwai Chan, S. (2004). A micromechanical analysis of the yielding behavior of individual widmanstätten colonies of an $\alpha+\beta$ titanium alloy. Metallurg. Mater. Trans. A. 35, 3409-3422. doi: 10.1007/s11661-004-0177-6

Lee, H. P., Esling, C., and Bunge, H. J. (1988). Development of the rolling texture in titanium. Texture Stress Microstruct. 7, 317-337. doi: 10.1155/TSM.7.317

Leyens, C., and Peters, M. (2003). Titanium and Titanium Alloys. Weinheim: John Wiley \& Sons. doi: 10.1002/3527602119

Li, H., Mason, D. E., Bieler, T. R., Boehlert, C. J., and Crimp, M. A. (2013). Methodology for estimating the critical resolved shear stress ratios of $\alpha$ phase $\mathrm{Ti}$ using EBSD-based trace analysis. Acta Mater. 61, 7555-7567. doi: 10.1016/j.actamat.2013.08.042

Li, W., Chen, Z., Liu, J., Wang, Q., and Sui, G. (2017). Effect of texture on anisotropy at $600{ }^{\circ} \mathrm{C}$ in a near- $\alpha$ titanium alloy Ti60 plate. Mater. Sci. Eng. A. 688, 322-329. doi: 10.1016/j.msea.2017.01.098

Li, W., Chen, Z., Liu, J., Zhu, S., Sui, G., and Wang, Q. (2019). Rolling texture and its effect on tensile property of a near- $\alpha$ titanium alloy Ti60 plate. J. Mater. Sci. Technol. 35, 790-798. doi: 10.1016/j.jmst.2018.10.032

Lutjering, G. (1998). Influence of processing on microstructure and mechanical properties of (a+b) titanium alloys. Mater. Sci. Eng. A. 243, 32-45. doi: 10.1016/S0921-5093(97)00778-8

Nalla, R. K., Ritchie, R. O., Boyce, B. L., Campbell, J. P., and Peters, J. O. (2002). Influence of microstructure on high-cycle fatigue of Ti-6Al-4V: Bimodal vs. lamellar structures. Metallurg. Mater. Trans. A 33, 899-918. doi: 10.1007/s11661-002-0160-z

Semiatin, S. L., and Bieler, T. R. (2001). The effect of alpha platelet thickness on plastic flow during hot working of TI-6Al-4V with a transformed microstructure. Acta Mater. 49, 3565-3573. doi: 10.1016/S1359-6454(01)00236-1

Singh, A. K., and Schwarzer, R. A. (2000). Texture and anisotropy of mechanical properties in titanium and its alloys. Zeitschrift fur Metallkunde. 919, 702-716. 
Tan, C., Li, X., Sun, Q., Xiao, L., Zhao, Y., and Sun J. (2015). Effect of a-phase morphology on low-cycle fatigue behavior of TC21 alloy. Int. J. Fatigue. 75, 1-9 doi: 10.1016/j.ijfatigue.2015.01.010

Taylor and Francis Group. (2010). Introduction to Texture Analysis. (Boca Raton, FL: CRC Press), 21-27.

Thomas Bieler, R., and Semiatin, S. L. (2002). The origins of heterogeneous deformation during primary hot working of Ti-6Al-4V. Int. J. Plasticity. 18, 1165-1189. doi: 10.1016/S0749-6419(01)00057-2

Wang, X. X., Zhan, M., Fu, M. W., Gao, P. F., Guo, J., and Ma, F. (2018). Microstructure evolution of Ti-6Al-2Zr-1Mo-1V alloy and its mechanism in multi-pass flow forming. J. Mater. Process. Technol. 261, 86-97 doi: 10.1016/j.jmatprotec,.2018.06.002

Won, J. W., Kim, D., Hong, S.-G., and Lee, C. S. (2016). Anisotropy in twinning characteristics and texture evolution of rolling textured high purity alpha phase titanium. J. Alloys Compd. 683, 92-99. doi: 10.1016/j.jallcom.2016. 05.029

Won, J. W., Park, K.-T., Hong, S.-G., and Lee, C. S. (2015). Anisotropic yielding behavior of rolling textured high purity titanium. Mater. Sci. Eng. A 637, 215-221. doi: 10.1016/j.msea.2015. 03.096

Wu, G. Q., Shi, C. L., Sha, W., Sha, A. X., and Jiang, H. R. (2013). Effect of microstructure on the fatigue properties of Ti-6Al-4V titanium alloys. Mater. Design 46, 668-674 doi: 10.1016/j.matdes.2012.10.059

Yan, S., Song, G.-L., Li, Z., Wang, H., Zheng, D., Cao, F., et al. (2018). A state-of-the-art review on passivation and biofouling of $\mathrm{Ti}$ and its alloys in marine environments. J. Mater, Sci. Technol. 34, 421-435. doi: 10.1016/j.jmst.2017.11.021

Yoo, M., and Wei, H. C. T. (1967). Slip modes of hexagonal-close-packed metals. J. Appl. Phys. 38, 4317-4322. doi: 10.1063/1.1709121

Zhang, L., and Chen, L. (2019). A review on biomedical titanium alloys: recent progress and prospect. Adv. Eng. Mater. 21:1801215doi: 10.1002/adem.201801215

Zhang, L., Chen, L., and Wang, L. (2020). Surface modification of titanium and titanium alloys: technologies, developments, and future interests. Adv. Eng. Mater. 1901258. doi: 10.1002/adem.201901258

Conflict of Interest: YW and BZ are employees of the 725 Research Institute of China Shipbuilding Industry Corporation.

The remaining authors declare that the research was conducted in the absence of the commercial relationships that could be construed as a potential conflict of interest.

Copyright () 2020 Fan, Huang, Xue, Zhang, Wang, Zhang, Tang, Zhao, Kou and Li. This is an open-access article distributed under the terms of the Creative Commons Attribution License (CC BY). The use, distribution or reproduction in other forums is permitted, provided the original author(s) and the copyright owner(s) are credited and that the original publication in this journal is cited, in accordance with accepted academic practice. No use, distribution or reproduction is permitted which does not comply with these terms. 